\title{
Erratum to: Efficacy and safety of Hybrid-APC for the ablation of Barrett's esophagus
}

\author{
Hendrik Manner ${ }^{1}$ Andrea May $^{2}$ - Ioanna Kouti ${ }^{1}$ - Oliver Pech ${ }^{3} \cdot$ Michael Vieth $^{4}$. \\ Christian Ell ${ }^{2}$
}

Published online: 31 December 2015

(C) Springer Science+Business Media New York 2015

\section{Erratum to: Surg Endosc \\ DOI 10.1007/s00464-015-4336-1}

The following footnote was inadvertently omitted from the first page of the article:

Parts of the study were used for the doctoral thesis of Ioanna Kouti.

The online version of the original article can be found under doi:10.1007/s00464-015-4336-1.

Hendrik Manner

HSManner@gmx.de

1 Department of Internal Medicine II, HSK Hospital, Teaching Hospital of the University Medicine of Mainz, Ludwig-

Erhard-Strasse 100, 65199 Wiesbaden, Germany

2 Department of Internal Medicine, Sana Klinikum, Offenbach, Germany

3 Department of Gastroenterology and Interventional Endoscopy, St. John of God Hospital, Regensburg, Germany

4 Institute of Pathology, Bayreuth Hospital, Bayreuth, Germany 